\title{
Molecular and clinical analysis of Ellis-van Creveld syndrome in the United Arab Emirates
}

\author{
Bassam R Ali ${ }^{*}$, Nadia A Akawi ${ }^{1}$, Faris Chedid ${ }^{2}$, Mahmood Bakir ${ }^{3}$, Moghis Ur Rehman², Aiman Rahmani ${ }^{2}$ \\ Lihadh Al-Gazali4
}

\begin{abstract}
Background: Ellis-van Creveld (EvC) syndrome is an autosomal recessive chondrodysplastic condition with clinical manifestations that include short-limbs and ribs, postaxial polydactyly and dysplastic nails and teeth. In about two thirds of patients, mutations in either EVC or EVC2 genes have been found to be the underlying cause.

Methods: In this paper, we describe the molecular (DNA sequencing) and clinical analysis of six children diagnosed with EvC from four different families from the United Arab Emirates (UAE).

Results: All the children had the common clinical and radiological features of this syndrome. However, DNA sequence analysis of the genes shown to be involved (EVC and EVC2) revealed a novel splice site mutation (c.2047$1 \mathrm{G}>T$ ) in intron 13 of EVC2 gene in one family. In addition, we confirm previous mutational analyses that showed a truncating mutation in exon 13 of EVC gene (c.1813C>T; p.Q605X) in the second family and a single nucleotide deletion (c.981delG; p.K327fs) in exon 8 of EVC2 gene in the third family. No mutations in the exons, splice sites or the promoter regions of either gene have been found in the index case of the fourth family who exhibited "EvC-like" features.
\end{abstract}

Conclusions: Given the small population size of UAE, our data illustrates further the molecular heterogeneity observed in EvC patients and excludes the possibility of a common founder effect for this condition in the UAE reflecting the current ethnic diversity of the country.

\section{Background}

Ellis-van Creveld syndrome (EvC, MIM 225500) is a chrondro-ectodermal dysplasia characterized by Richard Ellis and Simon van Creveld [1]. This condition is inherited in an autosomal recessive manner and typically involves malformations of certain cartilages especially those derived from "neural crest" cells, polydactyly and congenital heart defects in about 50 to $60 \%$ of the affected individuals [2]. EvC is a relatively rare disorder with only around 300 cases reported worldwide and is most prevalent in the Amish population of USA and some Arab populations [3-5]. Consanguinity has been reported in about $30 \%$ of the cases [6]. The birth prevalence in non-Amish population is estimated to be $0.7 /$ 100,000 of live birth [7]. However, in the UAE, AlGazali et al. [4] calculated the birth rate of this

\footnotetext{
* Correspondence: bassam.ali@uaeu.ac.ae

'Department of Pathology, Faculty of Medicine and Health Sciences, United Arab Emirates University, PO Box 17666, Al-Ain, United Arab Emirates
}

syndrome to be $5.2 / 100,000$ of live births, representing a useful baseline for this group of birth defects in the local society.

The EvC underlying gene was mapped to chromosome 4 p16 [8] and mutations have been found in the EVC gene by Ruiz-Perez et al. [3]. Mutations in a second gene EVC2, which is arranged in a head to head orientation with the EVC gene on chromosome 4, have also been identified as causative of the disease in a number of patients [9]. More recently, more mutations have been reported in both $E V C$ and $E V C 2$ in two thirds of $\mathrm{EvC}$ patients suggesting molecular heterogeneity of this condition and the possibility of the involvement of other gene(s) [10]. While $E V C$ gene has 21 coding exons that produce a 992 amino acid protein, $E V C 2$ gene has 22 coding exons and encodes a 1,308 amino acid protein without any homology to each other or to any other protein family [11]. In most cases, affected individuals with mutations in $E V C$ and $E V C 2$ have the typical spectrum of features and are phenotypically indistinguishable [11]. However, recent 
findings by Ulucan et al. [6] indicated that there is a considerable phenotypic variation in EvC highlighted by the analysis of a large family that exhibited complex septal cardiac defects, rhizomelic limb shortening and polydactyly without the typical lip, dental or nail abnormalities. The underlying genotype for this milder phenotype was reported to be a missense mutation (p.L623P) in EVC gene [6]. In this study we report the molecular analysis and clinical phenotyping of six individuals from the UAE with EvC. Our main findings are the identification of a novel splice site mutation in $E V C 2$ gene and the illustration of the molecular heterogeneity of this condition among UAE patients.

\section{Methods}

\section{Patients}

The research was approved by Al Ain Medical District Human Research Ethics Committee (07/114 and RECA/ 95/19). Patients were evaluated clinically by experienced neonatologists and a clinical geneticist. The criteria for inclusion were either: 1) postaxial polydactyly and radiographic evidence of $\mathrm{EvC}$ (short limbs, short ribs and characteristic pelvis), or 2) short limbs and short ribs with dysplastic nails or multiple frenulae if radiographs were not available [10]. Informed consent was obtained from the parents. The pedigrees of families affected are shown in Figure 1.

\section{Family 1 (UAE/Yemini)}

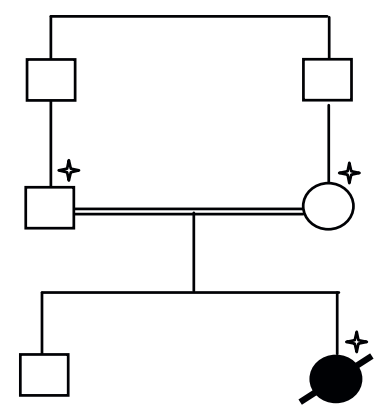

Family 3 (Egyptian)

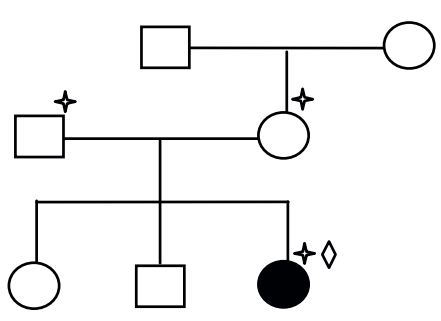

Family 2 (Sudanese)

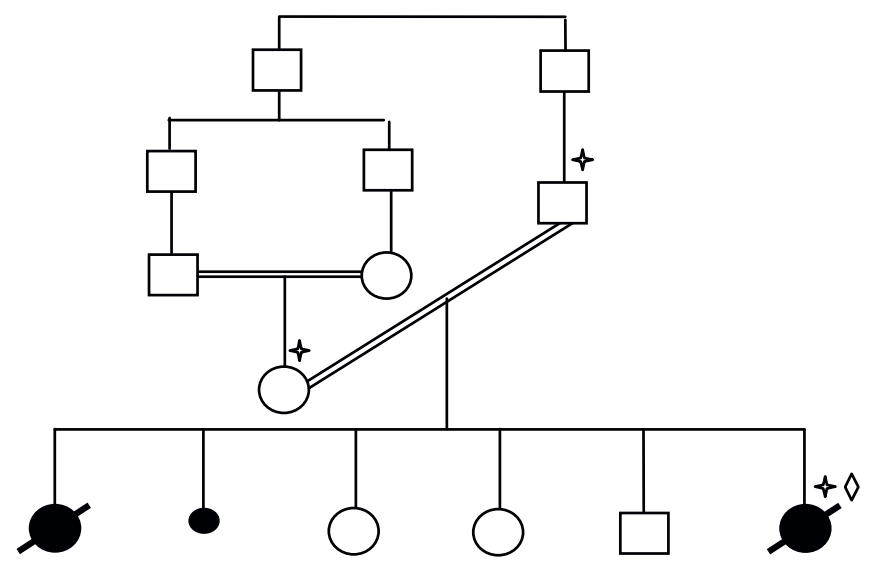

Family 4 (UAE/Afghani)

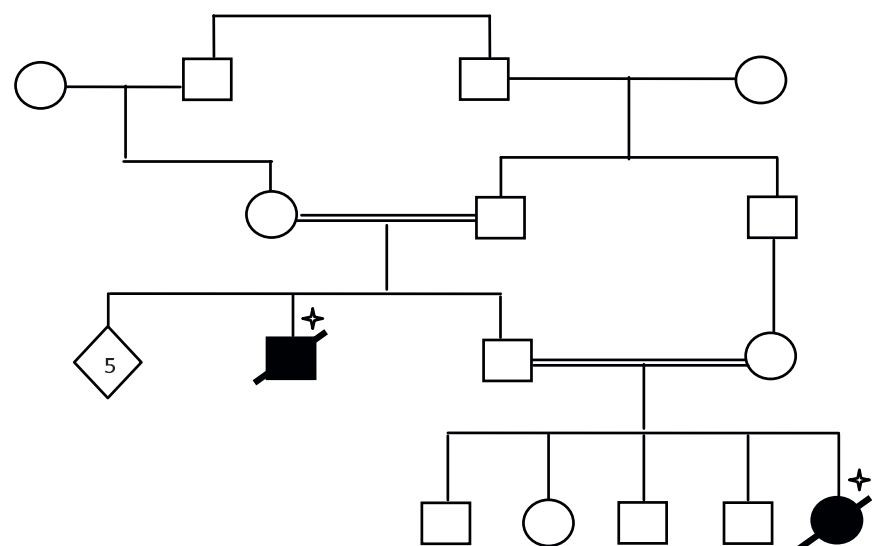

Figure 1 Pedigrees of the families involved in this study. The pedigrees shows consanguinity in three of the families affected with EvC. The plus sign indicates that the individual have been tested by the authors and the diamond indicates that the individual have been reported in Tompson et al [10]. 


\section{Genomic DNA Isolation}

Genomic DNA was extracted from whole blood using the Flexigene DNA Kit (Qiagen, $\mathrm{GmbH}$ ) according to the manufacturer's instructions or other standard technique.

\section{Polymerase Chain Reaction (PCR)}

The primers shown in additional file 1 were designed using Primer3 http://frodo.wi.mit.edu/primer3/ and used to screen genomic DNA for mutations in the promoter regions and all coding exons and at least $100 \mathrm{bp}$ of the flanking intron regions including the splice sites of $E V C$ and $E V C 2$ genes http://genome.ucsc.edu/. The promoter regions of $E V C$ and $E V C 2$ genes were predicted using the free online Proscan Version 1.7 software http:// www-bimas.cit.nih.gov/molbio/proscan/. PCR reactions consisted of $1.5 \mu \mathrm{M} \mathrm{MgCl} 2,5 \mu \mathrm{M}$ each of forward and reverse primers, $100 \mathrm{ng}$ DNA template, $0.2 \mathrm{mM}$ of each dNTP, 0.5 Units Taq DNA Polymerase (Qiagen, GmbH) and $1 \times$ PCR buffer (Qiagen, $\mathrm{GmbH}$ ), in a total volume of $20 \mu \mathrm{l}$. Reactions were started by $10 \mathrm{~min}$ DNA denaturation at $95^{\circ} \mathrm{C}$, followed by 40 cycles of the following PCR programme: $30 \mathrm{sec}$ at $95^{\circ} \mathrm{C}, 45 \mathrm{sec}$ at $58^{\circ} \mathrm{C}$, and 45 sec at $72^{\circ} \mathrm{C}$; the PCR was completed by a single cycle of $7 \mathrm{~min}$ at $72^{\circ} \mathrm{C}$.

\section{DNA sequencing}

After PCR, products were cleaned by treatment with ExoSAP-IT according to the manufacturer's protocol (USB, USA). Both strands of each amplicon were sequenced using the corresponding forward and reverse PCR primers (additional file 1). $10 \mu \mathrm{l}$ of cycle sequencing reactions consisted of: $4 \mu \mathrm{l}$ BigDye Mix (ABI, Foster City, CA); $1 \mu \mathrm{l}$ primer $(3.2 \mu \mathrm{M})$; and $1-3 \mu \mathrm{l} \mathrm{PCR}$ product were cycled 25 times $10 \mathrm{sec}$ at $96^{\circ} \mathrm{C}, 5 \mathrm{sec}$ at $50^{\circ} \mathrm{C}$, and $4 \mathrm{~min}$ at $60^{\circ} \mathrm{C}$. Purified reactions were then analyzed on an ABI 3130xl Genetic Analyzer (ABI, Foster City, CA) based at the Faculty of Medicine and Health Sciences, UAE University.

\section{Results}

\section{Patients' phenotypes}

The clinical phenotypes of the patients are summarized in table 1 and detailed bellow:

\section{Family 1}

This baby was the second child of first cousin UAE parents of Yemini origin (Figure 1). There was no family history of similar problems and the pregnancy and delivery were normal. Multiple congenital anomalies were diagnosed prenatally. At birth the baby needed intubation and ventilation. Examination at birth revealed a weight of $2215 \mathrm{gm}(<5 \%)$, length of $43 \mathrm{~cm}(<5 \%)$ and head circumference of $33.5 \mathrm{~cm}(<25)$. The baby was found to have dysmorphic features with narrow chest with short limbs (all elements), postaxial polydactyly and hypoplastic nails (Table 1). Echocardiography showed common atrium with dilated coronary sinus. The baby developed severe pulmonary hypertension secondary to lung hypoplasia which was resistant to treatment and died in the first 2 months of life. Skeletal

Table 1 Clinical features of cases from 4 families with EvC syndrome

\begin{tabular}{|c|c|c|c|c|}
\hline Features & Case 1 & Case 2 & Case 3 & Case 4 \\
\hline Ethnic origin & UAE/Yemini & Sudan & Egypt & UAE/Afghani \\
\hline$\underline{\mathrm{CHD}}$ & Common atrium with dilated coronary sinus & $?$ & AV canal defect & ASD \\
\hline \multicolumn{5}{|l|}{ Facial Features } \\
\hline Short/thin upper lip & + & + & + & + \\
\hline Short/multiple frenula & + & + & + & + \\
\hline$\underline{\text { Irregular alveolar ridge }}$ & + & + & + & + \\
\hline Natal teeth & - & + & + & + \\
\hline Short broad nose & + & + & + & + \\
\hline Long philtrum & + & + & + & + \\
\hline \multicolumn{5}{|l|}{ Skeletal features } \\
\hline Postaxial polydactyly & Hands, right & Hands, bilateral & Hands, bilateral & Hands and feet, bilateral \\
\hline Limb shortening & Mesomelic & Mesomelic & Mesomelic & Mesomelic \\
\hline Narrow chest & + & + & + & + \\
\hline Nail hypoplasia & + & + & + & $+/-$ \\
\hline \multicolumn{5}{|l|}{$\underline{\underline{\text { Radiological Features }}}$} \\
\hline Short long bones & + & + & + & + \\
\hline Short ribs with narrow chest & + & + & + & + \\
\hline Small iliac bones with downward spike & + & + & + & \\
\hline
\end{tabular}


survey showed short long bones with short ribs with narrow and long thorax. The iliac bones appeared small with a downward spike. The terminal phalanges of the toes were hypoplastic (Figure 2a \&2b).

\section{Family 2}

The parents are first cousin once removed (Figure 1) originally from Sudan and they had 5 children, 2 of them were affected. There was a history of one

\section{$2 \mathrm{~A}$}

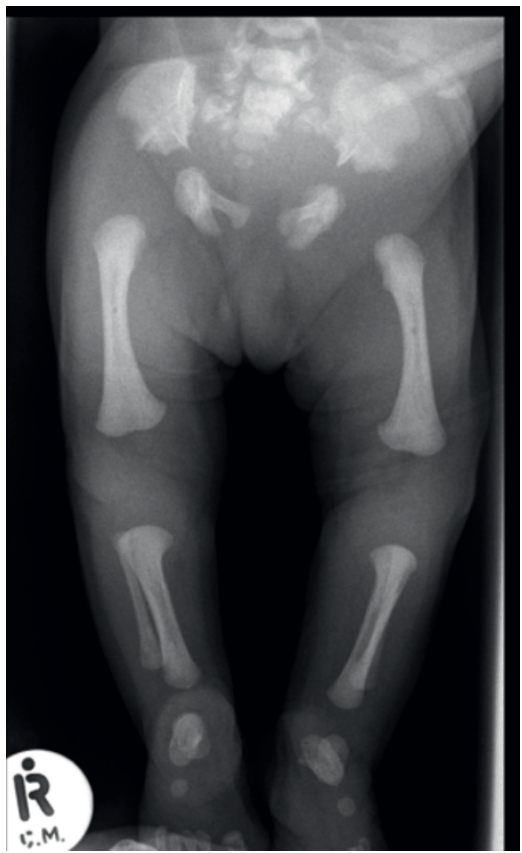

\section{B}

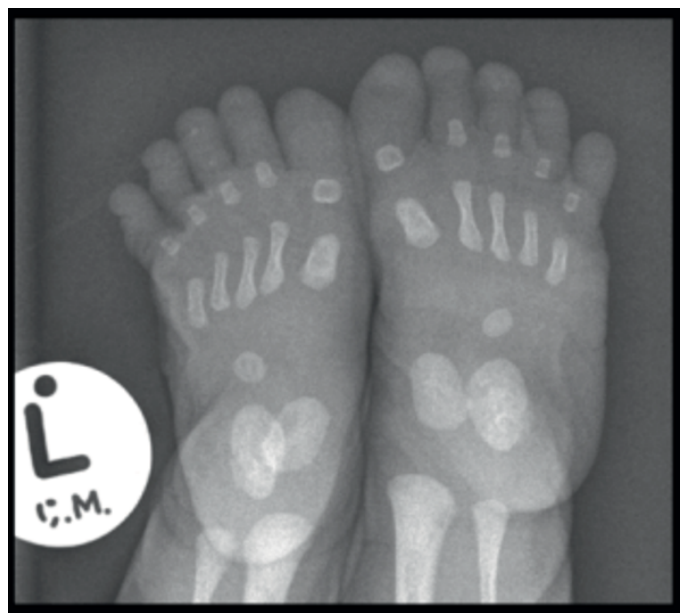

Figure 2 A X-ray of the lower limbs in case 3, note small iliac bones with triradiant acetabulum, short and thick long bones. 1B) X-ray of the feet in case 3 showing hypoplasia of the terminal phalanges. miscarriage. The first affected had the typical features of EvC and died on the second day of life. No DNA was available from this child. The second affected was diagnosed prenatally by ultrasound. She died half an hour after birth. No birth measurements were available. There was distal shortening of the limbs, postaxial polydactyly of both hands with hypoplastic nails, narrow chest, and distended abdomen with enlarged liver. She had the facial and oral features of EvC syndrome (Table 1). Skeletal survey showed short long bones with short ribs with narrow and long thorax. The iliac bones appeared small with a downward spike (Table 1).

\section{Family 3}

This patient was the third child of unrelated parents of Egyptian origin (Figure 1). The first 2 children were healthy. There was a history of postaxial polydactyly in the paternal grandfather. The pregnancy and delivery were normal. The patient birth weight was $3600 \mathrm{gm}$ (>25\%), length $45 \mathrm{~cm}(<5 \%)$, and head circumference 34 $\mathrm{cm}(50 \%)$. At birth she was noted to have a narrow chest with shortening of the distal segments of all limbs with bilateral postaxial polydactyly of the hands and hypoplastic fingernails and toenails. Echocardiography showed complete AV canal defect. This was corrected at 6 months of age. Ultrasound of the brain and kidneys were normal. Skeletal survey confirmed the diagnosis of EVC syndrome (Table 1).

\section{Family 4}

This is a highly inbred UAE family originally from Afghanistan (Figure 1). There were 2 affected children in 2 branches (the proband and her uncle from the father's side). The proband was a female and the product of normal pregnancy and delivery. Her birth weight was $2500 \mathrm{gm}(>5 \%)$ and length was $42 \mathrm{~cm}(<5 \%)$. She was noted to have dysmorphic features with short limbs with bilateral postaxial polydactyly of the upper and lower limbs, very narrow chest with hypoplastic lungs (Table 1). The nails were noted to be normal. Echocardiography revealed atrial septal defect (ASD). Skeletal survey showed short ribs with long and narrow thorax, short long bones and typical changes in the pelvis. She had repeated chest infections requiring intensive care unit (ICU) care on many occasions. At 2 years of age she was oxygen dependant and had normal intelligence. She died at the age of 3 years due to respiratory complications. The uncle of the proband who was the product of first cousin marriage was also affected. He was the product of normal pregnancy and delivery. At birth he was noted to have short limbs with bilateral post axial polydactyly of upper and lower limbs, hypoplastic nails, narrow chest. There were short frenula and natal teeth. There was a murmur at the left sternal edge suggestive of ASD. The baby died in the first few weeks of life due to respiratory complications. Due to lack of an obvious 
pathogenic mutation in either $E V C$ or $E V C 2$ genes we consider the diagnosis of $\mathrm{EvC}$ in this family tentative and therefore we refer to it as "EvC-Like" syndrome. Unfortunately, X-rays are not available for the affected members of this family.

\section{Patients' genotypes}

Screening for sequence variations in $E V C$ and $E V C 2$ genes was conducted by analyzing the DNA sequencing chromatograms for heterozygosity and alignment of the obtained sequence for each amplicon with its corresponding original genomic sequence http://genome.ucsc. edu/ using ClustalW2 http://www.ebi.ac.uk/Tools/clustalw2/index.html. We have identified a splice site homozygous change (c.2047-1G>T) in intron 13 of $E V C 2$ gene for the index case of family 1 (Figure $3 \mathrm{~A}$ ). This mutation has not been found in 100 ethnically matched controls. We also confirm the presence of a missense mutation (c.1813C>T; p.Q605X) in exon 13 of $E V C$ gene for the case index in family 2 (Figure $3 \mathrm{~B}$ ) and a deleted G (c.981delG; p.K327fs) in exon 8 of $E V C 2$ gene for the index case of family 3 (Figure $3 \mathrm{C}$ ); presence of these mutations in members of those families have been previously reported [10]. The parents were tested where DNA samples were available and found to be heterozygous for the relevant mutation (not shown). Single nucleotide polymorphisms (SNPs) in EVC and EVC2 genes were also identified in the index case with the novel mutation of family 1 in (Table 2). No mutations in either $E V C$ or $E V C 2$ genes were detected in the DNA from the index case of family 4 .

\section{Discussion}

Consanguineous marriages in Arab and Middle Eastern populations are very common leading to a disproportionate number of recessive disorders within these populations [12]. This situation is exacerbated by the limited opportunities for prenatal diagnosis, carrier screening and other preventative approaches. A prerequisite for any preventative approaches is the identification of the exact molecular defects underlying those disorders. In this paper, we aimed to identify and document the molecular causes underlying Ellis van Creveld syndrome in UAE population. The UAE population is ethnically heterogeneous with significant ethnic groups originating from Arabia, Persia, Baluchistan, Asia and East Africa. In addition, the majority of the current population is expatriates from the Indian subcontinent, other Middle Eastern countries and Europe. Therefore our findings might have impact on diagnosis and prevention of this condition in neighboring countries. Our data indicate the molecular heterogeneity of this condition in UAE population (Table 3). We identified four families with either typical features of the condition or
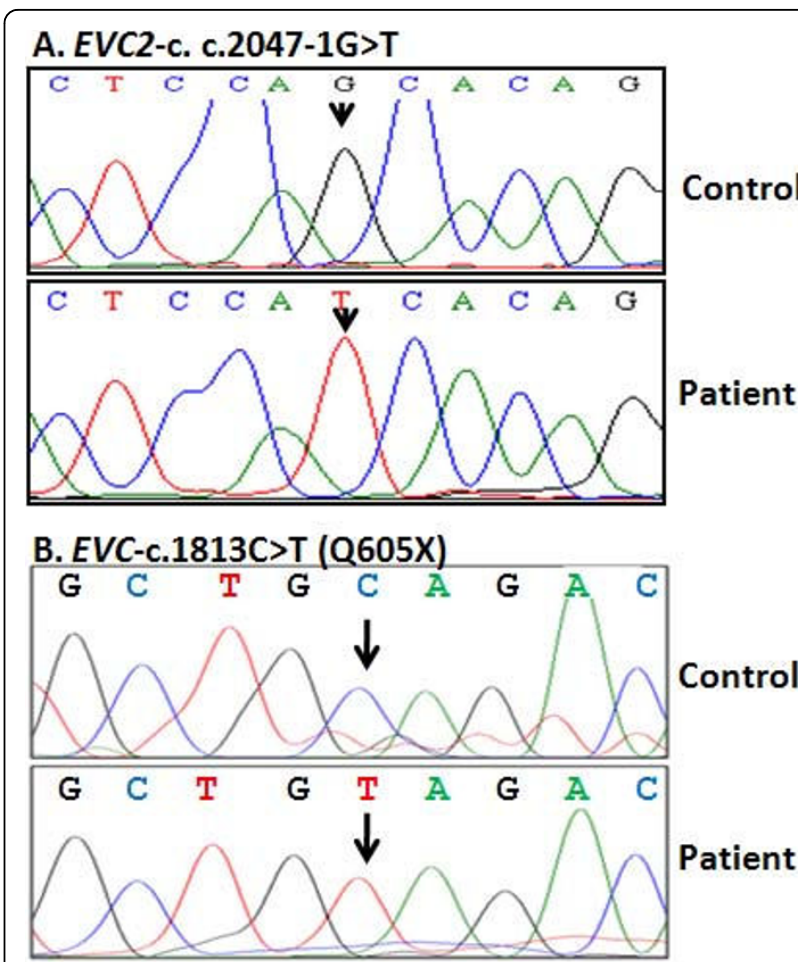

C. EVC2-c.981delG (p.K327fs)

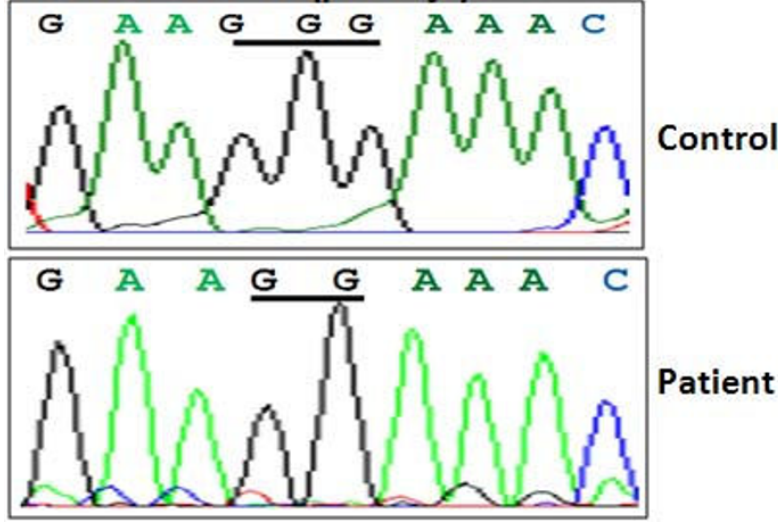

Figure 3 Sequence chromatograms of mutations found in EVC or EVC2 genes from EvC patient from UAE. A) Chromatograms showing the novel splice site mutation c.2047-1G>T in intron 13 of EVC2 gene. B) Chromatograms of the missense mutation c.1813C>T in exon 13 of ECV gene. C) Chromatograms of the C.981delG in exon 8 of EVC2 gene in case 3.

have "EvC-like" symptoms. All affected children in this study satisfied the clinical diagnostic criteria for $\mathrm{EvC}$ syndrome $[6,10]$. However, the absence of mutations in either $E V C$ or $E V C 2$ genes in family number 4 makes the diagnosis likely but not confirmed in this family and we therefore refer to the condition in this family as "EvC-like" syndrome. Other conditions with similar manifestations, like Weyers acrofacial dysostosis and Jeune thoracic dystrophy, were also considered in the differential diagnosis. Weyers acrofacial dysostosis is an 
Table 2 SNPs identified in EVC and EVC2 genes in the index case of family 1 with the novel mutation

\begin{tabular}{|c|c|c|c|c|}
\hline dbSNPs & Gene & Reference Number & Minor Allele Frequency ${ }^{a}$ & Average Heterozygosity $^{\mathrm{b}}$ \\
\hline NM_153717.2:c.769 C>T & EVC & rs6446393 & C:0.04 & - \\
\hline NM_153717.2:c.772 T>C & EVC & rs6414624 & $\mathrm{T}: 0.13$ & $0.351+/-0.229$ \\
\hline NM_153717.2:c.939+4T>C & EVC & rs2286343 & $\mathrm{T}: 0.43$ & $0.480+/-0.098$ \\
\hline NM_153717.2:c.969 T>C & EVC & rs4688963 & $\mathrm{T}: 0.47$ & $0.500+/-0.014$ \\
\hline NM_153717.2:c.1026 G>C & EVC & rs4688962 & G:0.37 & $0.461+/-0.135$ \\
\hline NM_153717.2:c.1854C>T & EVC & rs11737221 & - & - \\
\hline NM_153717.2:c.2305-8A>T & EVC & rs1031919 & $\mathrm{T}: 0.48$ & $0.441+/-0.162$ \\
\hline NM_153717.2:c.2894+18G>A & EVC & rs2279250 & A:0.43 & $0.499+/-0.020$ \\
\hline NM_153717.2:c.*14G>A & EVC & rs2291151 & A:0.01 & $0.496+/-0.045$ \\
\hline NM_147127.3:c. 2151C>T* & EVC2 & unknown & - & - \\
\hline NM_147127.3:c.3507C>T & EVC2 & rs12511039 & $C: 0.50$ & $0.482+/-0.093$ \\
\hline
\end{tabular}

${ }^{\mathrm{a}}$ Available from http://www.ncbi.nlm.nih.gov/SNP/

${ }^{\mathrm{b}}$ Available from http://www.genecards.org

*Silent change appeared in 4 out of 200 normal alleles.

Table 3 Summary of mutations found in EvC patients from UAE

\begin{tabular}{lcclc}
\hline Case & Gene & $\begin{array}{c}\text { DNA } \\
\text { change* }\end{array}$ & $\begin{array}{c}\text { Protein } \\
\text { Change }\end{array}$ & Reference \\
\hline Family 1 & EVC2 & c.2047-1G>T & splicing & This study \\
\hline Family 2 & EVC & c.1813C>T & p.Q605X & $\begin{array}{c}\text { Tompson et al., } \\
2007\end{array}$ \\
\hline Family 3 & EVC2 & c.981delG & p.K327fs & $\begin{array}{c}\text { Tompson et al., } \\
2007\end{array}$ \\
\hline Family 4 & - & unknown & NA & This study
\end{tabular}

*EVC and EVC2 mutations numbering is based on their CDNA sequences of the GenBank accession numbers NM_153717.2 and NM_147127.4 respectively with +1 as the $A$ of the ATG initiation codon.

autosomal dominant disorder characterized by postaxial polydactyly, dysplastic nails, oligodontia with conical teeth and short stature caused by short limbs. This condition is allelic to $\mathrm{EvC}$ syndrome and is caused by heterozygous mutation in $E V C 2$ gene [13]. Patients with this syndrome however, are less severely affected than $\mathrm{EvC}$ and they do not have narrow chest. In addition, the mode of inheritance is autosomal dominant rather than recessive. Jeune thoracic dystrophy is an autosomal recessive condition characterized by very narrow chest with variable shortening of the limbs. Postaxial polydactyly can also be a manifestation in half of the cases. The limb shortening is usually rhizomelic rather than mesomelic as in $\mathrm{EvC}$ syndrome and there is usually no oral manifestation, and no nail dysplasia [14]. All the children in this report including members of family 4 had oral manifestations and nail dysplasia making the diagnosis of Jeune thoracic dysplasia unlikely.

Molecular study on the 4 families identified a novel splice site mutation (c.2047-1G>T) in intron 13 of $E V C 2$ gene in one of these families and confirmed two mutations in two other families; a nonsense mutation
(c.1813C>T; p.Q605X) in exon 13 of $E V C$ gene and a single nucleotide deletion (c.981delG; p.K327fs) in exon 8 of $E V C 2$ gene [10]. RNA from the effected members of the family with the novel splice site mutation was not available for to demonstrate its altered RNA splicing effects. The lack of mutation in $E V C$ and $E V C 2$ genes in the $4^{\text {th }}$ family could indicate incorrect diagnosis or molecular heterogeneity of the condition. However, both affected children in this family had postaxial polydactyly, oral manifestations of EvC syndrome, limb shortening, congenital heart defect (ASD) typically seen in EvC syndrome and one of them had dysplastic nails making the diagnosis of EvC syndrome most likely and hence we refer to it to "EvC-like" syndrome. However, it is possible that lack of mutation in $E V C$ and $E V C 2$ genes in this family is due to genetic heterogeneity of this disorder as was suggested by Tompson et al. [10] who sequenced $E V C$ and $E V C 2$ genes in 65 individuals affected by EvC. They reported mutations in either $E V C$ or $E V C 2$ in only two thirds of their patients with the remaining of unknown molecular cause. From these studies, we anticipate the existence of another EvC causative gene(s). Further studies are needed to clarify the underlying cause of $\mathrm{EvC}$ in this group of patients.

\section{Conclusions}

We conclude that $\mathrm{EvC}$ in the UAE population is heterogeneous at the molecular level which reflects the ethnic diversity of the current population in the country.

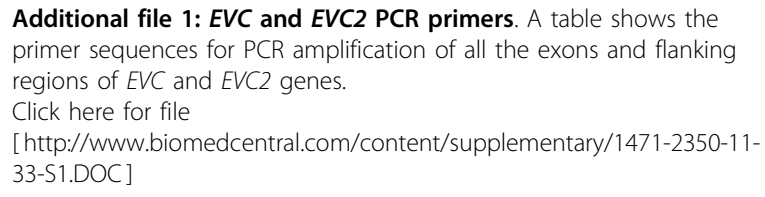




\section{Acknowledgements}

We thank the Dubai Harvard Foundation for Medical Research for the financial support of this project. We also thank the affected families for their cooperation on this project.

\section{Author details}

Department of Pathology, Faculty of Medicine and Health Sciences, United Arab Emirates University, PO Box 17666, Al-Ain, United Arab Emirates. 2Department of Paediatrics, Tawam Hospital, Al-Ain, United Arab Emirates. ${ }^{3}$ Department of Paediatrics, Al-Ain Hospital, Al-Ain, United Arab Emirates. ${ }^{4}$ Department of Paediatrics, Faculty of Medicine and Health Sciences, United Arab Emirates University, PO Box 17666, Al-Ain, United Arab Emirates.

\section{Authors' contributions}

Study design: BRA and LA. Clinical evaluation of patients and sample collection: LA, FC, MB, MUR and AR. Generation and analysis of data: NAA, BRA and LA. Preparation of the manuscript: BRA, LA and NAA. All the authors read and approved the final manuscript.

\section{Competing interests}

The authors declare that they have no competing interests.

Received: 8 April 2009 Accepted: 25 February 2010

Published: 25 February 2010

\section{References}

1. Ellis RWB, van Creveld S: A syndrome characterized by ectodermal dysplasia, polydactyly, chondrodysplasia, and congenital morbus cordis: report of three cases. Arch Dis Child 1940, 5:65.

2. McKusick VA, Egeland JA, Eldridge R, Krusen DE: Dwarfism in the Amish. I. The Ellis-van Creveld syndrome. Bull Johns Hopkins Hosp 1964, 115:306-336.

3. Ruiz-Perez VL, Ide SE, Strom TM, Lorenz B, Wilson D, Woods K, King L, Francomano C, Freisinger P, Spranger S, Marino B, Dallapiccola B, Wright M, Meitinger T, Polymeropoulos MH, Goodship J: Mutations in a new gene in Ellis-van Creveld syndrome and Weyers acrodental dysostosis. Nat Genet 2000, 24:283-286.

4. Al-Gazali L, Bakir M, Hamid Z, Varady E, Varghes M, Haas D, Bener A, Padmanabhan R, Abdulrrazzzaq YM, Dawodu AK: Birth prevalence and pattern of osteochondrodysplasias in an inbred high risk population. Birth Defects Res Part A Clin Mol Teratol 2003, 67:125-32.

5. Baujat G, Le Merrer M: Ellis-Van Creveld syndrome. Orphanet J Rare Dis 2007, 2:27.

6. Ulucan H, Gül D, Sapp JC, Cockerham J, Johnston JJ, Biesecker LG: Extending the spectrum of Ellis van Creveld syndrome: a large family with a mild mutation in the EVC gene. BMC Med Genet 2008, 9:92

7. Saneifard H, Amirhakimi G: Ellis van Creveld Syndrome: Report of a Case and Brief Literature Review. Iran J Pediator 2008, 18:75-78.

8. Polymeropoulos M, Ide S, Wright M, Goodship J, Weissenbach J, Pyeritz R, Da Silva E, Ortiz De Luna R, Francomano CA: The gene for the Ellis-van Creveld syndrome is located on chromosome 4p16. Genomics 1996, 35:1-5.

9. Galdzicka M, Patnala S, Hirshman MG, Cai JF, Nitowsky H, Egeland JA, Ginns El: A new gene, EVC2, is mutated in Ellis-van Creveld syndrome. Mol Genet Metab 2002, 77:291-295.

10. Tompson SW, Ruiz-Perez VL, Blair HJ, Barton S, Navarro V, Robson JL, Wright MJ, Goodship JA: Sequencing EVC and EVC2 identifies mutations in two-thirds of Ellis-van Creveld syndrome patients. Hum Genet 2007, 120:663-670

11. Ruiz-Perez VL, Tompson SWJ, Blair HJ, Espinoza-Valdez C, Lapunzina P, Silva EO, Hamel B, Gibbs JL, Young ID, Wright MJ, Goodship JA: Mutations in two nonhomologous genes in a head-to-head configuration cause Ellis-van Creveld syndrome. Am J Hum Genet 2003, 72:728-732.

12. Al-Gazali L, Hamamy H, Al-Arrayad S: Genetic disorders in the Arab world. BMJ 2006, 333:831-834

13. Ye X, Song G, Fan M, Shi L, Jabs EW, huaung S, Guo R, Bian Z: A novel heterozygous deletion in EVC2 gene causes Weyers acrofacial dysostosis. Hum Genet 2006, 119:199-205.

14. Jeune M, Beraud C, Carron R: Dystrophie thoracique asphyxiante de caractere familial. Arch Fr Pediatr 1955, 12:886.

\section{Pre-publication history}

The pre-publication history for this paper can be accessed here:http://www. biomedcentral.com/1471-2350/11/33/prepub

doi:10.1186/1471-2350-11-33

Cite this article as: Ali et al:: Molecular and clinical analysis of Ellis-van Creveld syndrome in the United Arab Emirates. BMC Medical Genetics 2010 11:33.

\section{Submit your next manuscript to BioMed Central and take full advantage of:}

- Convenient online submission

- Thorough peer review

- No space constraints or color figure charges

- Immediate publication on acceptance

- Inclusion in PubMed, CAS, Scopus and Google Scholar

- Research which is freely available for redistribution 